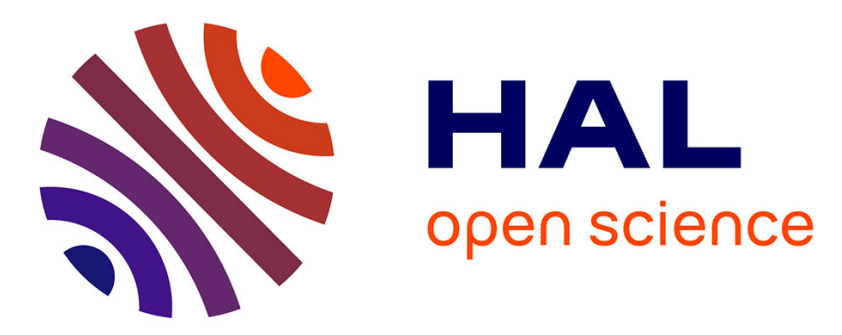

\title{
Accurate Measurement of Rare Earth Elements by ICP-MS after Ion-Exchange Separation: Application to Ultra-Depleted Samples
}

Marc Ulrich, Sarah Bureau, Catherine Chauvel, Christian Picard

\section{- To cite this version:}

Marc Ulrich, Sarah Bureau, Catherine Chauvel, Christian Picard. Accurate Measurement of Rare Earth Elements by ICP-MS after Ion-Exchange Separation: Application to Ultra-Depleted Samples. Geostandards and Geoanalytical Research, 2012, 36 (1), 10.1111/j.1751-908X.2011.00116.x . hal01257692

\section{HAL Id: hal-01257692 \\ https://hal.science/hal-01257692}

Submitted on 19 Jan 2016

HAL is a multi-disciplinary open access archive for the deposit and dissemination of scientific research documents, whether they are published or not. The documents may come from teaching and research institutions in France or abroad, or from public or private research centers.
L'archive ouverte pluridisciplinaire HAL, est destinée au dépôt et à la diffusion de documents scientifiques de niveau recherche, publiés ou non, émanant des établissements d'enseignement et de recherche français ou étrangers, des laboratoires publics ou privés. 


\title{
Accurate REE measurement by ICP-MS after ion exchange separation. Application to ultra-depleted samples.
}

\author{
Marc ULRICH ${ }^{1,2, *}$, Sarah BUREAU ${ }^{2}$, Catherine $\mathrm{CHAUVEL}^{2}$, and Christian PICARD $^{3}$ \\ 1. PPME, EA 3325, Université de la Nouvelle-Calédonie, 98851, Nouméa, New-Caledonia \\ 2. ISTerre, CNRS, Université Grenoble 1, BP 53, 38041 Grenoble, France \\ 3. UMR 6249 Chrono-environnement, Université de Franche Comté, 25000, Besançon, France \\ * corresponding author: marc.ulrich@ujf-grenoble.fr
}

January 2011, revised version for Geostandards and Geoanalytical Research 


\section{$\underline{\text { Abstract }}$}

This study reports precise and accurate data for rare earth elements (REE) measured on eight geological reference materials, five enriched in REE (BE-N, BHVO-2, BR, BR-24 and RGM-1) and three very depleted in REE (BIR-1, UB-N and DTS-2). Data were acquired by quadrupole ICP-MS after isolation of the REE using an ion-exchange chromatography procedure. All the measured REE abundances are similar within $\approx 5 \%(10 \%$ for the most REE-depleted sample DTS-2) to the high quality measurements previously published in the literature. We also show that using an internal Tm spike, the reproducibility of the data is improved to $\sim 1 \%$.

Applying this technique to the analysis of ultra-depleted rock samples (sub ng.g-1), we show that significant improvements are obtained relative to the routine trace element measurement method. The chondrite-normalized patterns are smooth instead of displaying irregularities. Although the classical method gives excellent results on REE-rich samples, we believe that our technique improves the precision and accuracy of measurements for highly REE-depleted rocks.

\section{$\underline{\text { Introduction }}$}

For decades, most geochemical studies use trace element data to identify geological processes such as melting of mantle sources or fractional crystallization of magmas (Henderson, 1984). In particular, the accurate determination of Rare Earth Element (REE) concentrations provides important information for the understanding of geological processes. Because of their high charge (trivalent cations except for $\mathrm{Ce}^{4+}$ under oxidizing conditions and $\mathrm{Eu}^{2+}$ under reducing conditions) and large radii, REE are incompatible elements during most mantle melting processes (White, 2003), and they are usually more abundant in melt-derived rocks than in residual ultramafic rocks. The extreme REE-depletion currently observed in the latter type of samples (sub ng. $\mathrm{g}^{-1}$ ) explains why it is so difficult to measure them accurately (e.g. Nakamura and Chang, 2007).

Quadrupole inductively coupled plasma-mass spectrometer (ICP-MS) is one of the most commonly used technique to quickly and precisely determine the REE concentrations, 
even at sub $\mu \mathrm{g} \cdot \mathrm{g}^{-1}$ concentrations in rock samples. Nevertheless, when the concentrations are lower, at the sub ng.g ${ }^{-1}$ level, measurements using quadrupole ICP-MS become problematic due to sensitivity limitation. For samples very depleted in REE, other methods might thus be preferred. Isotopic dilution coupled with thermal ionization mass spectrometry has a wellestablished reputation as it provides very precise data (i.e., Raczek et al., 2001). However, this method is time-consuming and only elements with more than one isotope can be measured. Other alternatives exist: for example, Willbold and Jochum (2005) use isotope dilution coupled to a sector field ICP-MS and Jain et al. (2000) use an ultrasonic desolvating nebulisation coupled to ICP-MS. These techniques provide very good data but they either require specific instruments or are significantly more time consuming than the usual ICP-MS analysis.

Nakamura and Chang (2007) reported recently precise REE data on highly depleted reference materials (PCC-1, DTS-1, DTS-2 and JP-1) using a quadrupole ICP-MS and appropriate mathematical corrections for oxide interferences. Although this method provides quite reproducible data $(\approx 5 \%, 1 \sigma)$, it is also possible to enhance the signal and reduce the oxide interferences by isolating the REE from the other elements present in the rock sample (Hirata et al. 1988, Barrat et al. 1996).

Here, we describe a procedure including chemical separation of the REE and measurement by quadrupole ICP-MS. Based on this procedure, we report results for REE contents in eight geological reference materials (BE-N, BHVO-2, BR, BR-24, RGM-1, BIR-1, UB-N and DTS-2) as well as few ultra-depleted peridotites from New Caledonia.

\section{$\underline{\text { Analytical method }}$}

\section{Chemical isolation of Rare Earth Elements}

The protocol described in this paper is adapted from the methods published by Strelow (1966) and Barrat et al. (1996). All procedures were carried out under cleanroom conditions, all acids $\left(\mathrm{HCl}, \mathrm{HNO}_{3}, \mathrm{HF}\right.$ and $\left.\mathrm{HClO}_{4}\right)$ were double distilled and de-ionized water (resistivity of $18.2 \mathrm{M} \Omega \mathrm{cm}^{-1}$ ) was used throughout the protocol.

About $50 \mathrm{mg}$ of sample powder is dissolved in a mixture of concentrated HF and $\mathrm{HCLO}_{4}(5: 1)$ in Teflon containers maintained in steel jacket PARR bombs at $140^{\circ} \mathrm{C}$ for five days to achieve complete dissolution. Samples are then transferred in clean Savillex teflon 
beakers and placed on a hot plate at $150^{\circ} \mathrm{C}$ until the $\mathrm{HF}-\mathrm{HCLO}_{4}$ mixture is completely evaporated. The residue is taken up in $3 \mathrm{~mL}$ of $6 \mathrm{~N} \mathrm{HCl}$ and a variable quantity (depending on the estimated REE concentration in the sample) of a Tm solution is added to samples in order to have a final Tm spike concentration of $\sim 15 \mathrm{ppb}$ (see supplementary table 1). The sample is heated at $100^{\circ} \mathrm{C}$ for 24 hours and finally evaporated. The dry residues are taken up in $2 \mathrm{~mL}$ of a mixture of $7 \mathrm{~N} \mathrm{HNO}_{3}-6 \mathrm{~N} \mathrm{HCl}(3: 1)$, fluxed for 12 hours, ultrasounded for 10 minutes and centrifuged for 5 minutes at $5000 \mathrm{rpm}$ to verify the absence of solid residue. If necessary, these latter crucial steps are repeated because the presence of a solid residue could entrain a loss of REE.

The $2 \mathrm{~mL}$ solution is loaded on a column (Biorad Poly-prep ${ }^{\circledR}$ columns) packed with 2 $\mathrm{mL}$ of 200-400 mesh Biorad ${ }^{\circledR}$ AG50W-X8 cation resin and calibrated to isolate REE from most other elements present in rocks. The resin is conditioned with $10 \mathrm{~mL}$ of a $7 \mathrm{~N} \mathrm{HNO}_{3}-6 \mathrm{~N}$ $\mathrm{HCl}$ (3:1) mixture. All elements except REE are removed using $8 \mathrm{~mL}(1+1+6 \mathrm{~mL})$ of $\mathrm{HNO}_{3}-$ $\mathrm{HCl}$ and REE are collected with $15 \mathrm{~mL}$ of $7 \mathrm{~N} \mathrm{HNO}_{3}$. A typical elution profile is shown in Figure 1 where we report counts for REE and other trace elements as measured in $2 \mathrm{~mL}$ acid fractions of an elution performed using a UB-N dissolution. Samples are then evaporated to dryness and a mixture of $1 \mathrm{~mL} 14 \mathrm{~N} \mathrm{HNO}_{3}$ and $0.5 \mathrm{~mL} 30 \% \mathrm{H}_{2} \mathrm{O}_{2}$ is added to the residue to destroy any resin potentially present in the beaker and finally dried down. Just before analysis on the ICP-MS, samples are taken up in a weighted quantity of $2 \% \mathrm{HNO}_{3}$ that is adjusted to the required dilution factor (see supplementary table 1).

\section{Instrumental, acquisition time and wash cycle}

Measurements were carried out using an Agilent 7500ce quadrupole ICP-MS (Agilent Technologies). Samples were introduced with a quartz Micromist-type nebulizer with a quartz spray chamber cooled at $2{ }^{\circ} \mathrm{C}$. The operating conditions are optimized for maximum sensivity on ${ }^{7} \mathrm{Li},{ }^{89} \mathrm{Y}$ and ${ }^{205} \mathrm{Tl}$ (typically $2 \mathrm{Mcps} / \mathrm{ppm}, 5 \mathrm{Mcps} / \mathrm{ppm}$ and $2.5 \mathrm{Mcps} / \mathrm{ppm}$, respectively). The complete operating conditions are listed in Table 1. Blank contribution and oxide production data are summarized in supplementary table 2 available on the GGR website.

Comparatively to light REE, heavy REE are generally less abundant in samples and thus counting statistics dictate that a longer acquisition time improves errors on the measurements. Therefore, two different acquisition times were chosen: a acquisition time of 0.60 second per mass for masses ranging from $137(\mathrm{Ba})$ to $163(\mathrm{Dy})$, and a longer acquisition 
time of 1.20 second per mass for the heavier REE $\left({ }^{165} \mathrm{Ho}\right.$ to $\left.{ }^{175} \mathrm{Lu}\right)$. The total acquisition time per sample is estimated at 57.5 seconds.

The wash cycle between samples was optimized to ensure complete washout and equilibration of the entire system. It includes a 10 seconds wash with de-ionized water followed by a 120 seconds wash with $5 \% \mathrm{HNO}_{3}$ and a 240 seconds wash with $2 \% \mathrm{HNO}_{3}$. These washout times were chosen so that the number of counts at the end of the washing cycle was similar to those measured during the first wash cycle, before any sample was measured.

\section{Calibration of the signal}

Calibration is performed using one blank solution and two different dilutions of the USGS natural reference material BHVO-2 that followed the same chemical separation as the samples. The set of REE concentrations used for BHVO-2 are those published by Eggins et al. (1997), but BHVO-2 was also measured as unknown: in this specific case, the signal was calibrated using the REE contents of BR published by Eggins et al. (1997) (see Table 2 for results). The choice of BHVO-2 as the best natural standard was dictated by two factors: (a) Chauvel et al. (in press) estimated that for an accurate determination of the trace element concentrations of samples as poor as BIR-1 or UB-N, it was better to calibrate the ICP-MS signal with a rock standard not too rich in trace elements; (b) even if the REE concentrations in BHVO-2 are not certified, BHVO-2 is one of the most analyzed geological reference material and its REE content is well constrained (fourth among the 100 most frequently requested reference materials on the GeoReM website; see GeoReM preferred values by Jochum and Nehring, 2006, and Jochum and Nohl, 2008). Finally, the blank and BHVO-2 solutions were analyzed every five samples during the entire sequence of measurements.

\section{Interference and analytical drift corrections}

Several studies showed that oxygen reacts with some elements to form oxides during analyzes on ICP-MS (e.g. Cheatham et al., 1993; Dulski, 1994; Aries et al., 2000; Newman et al., 2009). Oxides of the light REE (LREE) cause interferences on intermediate REE (MREE) and for accurate determination of the MREE, a correction is required. As described by Dulski (1994), we correct the oxide interferences using a correction factor calibrated daily with 
single element solutions of $\mathrm{Ba}$ and $\mathrm{Ce}$, and a solution of mixed $\mathrm{Pr}$ and $\mathrm{Nd}$. The main oxide interferences observed during the course of this work are listed in supplementary table 2.

When REE analyses are performed on samples simply dissolved but not chemically separated, $\mathrm{Ba}$ oxide interferences are significant and known to alter the results obtained for $\mathrm{Eu}$ contents (Dulski 1994, Aries et al. 2000, Nakamura and Chang 2007). In this case, corrections can represent up to $70 \%$ of the peak measured on mass 151 for highly depleted samples. In our study, this interference is considerably reduced due to the removal, through chemical isolation of the REE, of a large proportion of the Ba present in the sample ( $>80 \%)$ (Figure 1). Indeed, during the course of this study, the Ba oxide interference never represented more than $0.04 \%$ of the total counts measured on mass $151 \mathrm{(Eu)} \mathrm{(values} \mathrm{for} \mathrm{the} \mathrm{other} \mathrm{corrected} \mathrm{oxide}$ interferences are reported in supplementary table 2). Thus, complex interference corrections such as those described by Nakamura and Chang (2007) are not required here. Finally, instrumental drift was corrected using the drift on the Tm spike.

\section{Procedural blank and detection limits}

To quantify the exogenous pollution during the analytical procedure, procedural blanks were prepared following the same procedure as used for rock samples. The average REE contents of 10 blanks performed over 1 year are given in supplementary Table 2 . They range from 0.6 to $40 \mathrm{pg}$, values that are negligible relative to samples since the sample/blank ratio is at least higher than 100 for the most REE-depleted reference material DTS-2. Detection limits for all REE were determined as the concentration equivalent of three times the standard deviation of the procedural blank. Values expressed as rock equivalents are plotted in Figure 2 and are listed in supplementary Table 2 . They range from $\sim 1$ to 120 pg. $\mathrm{g}^{-1}$ values that compare favorably to values published in the literature (often 10 to 10000 pg.g-1, see for example Eggins et al., 1997 and Willbold and Jochum, 2005). Our detection limits are thus sufficiently low relative to the REE concentrations of all the reference materials analyzed in this work, even for the ultra-depleted sample DTS-2 (Figure 2).

\section{$\underline{\text { Results and discussion }}$}

The first analyzes were performed after chemical separation of the REE but without Tm spike addition. The REE signal was calibrated using two methods: pure REE solutions 
and a BHVO-2 solution. There is usually two different ways to calibrate the ICP-MS signal: multiple dilutions of synthetic solutions (e.g. Nakamura and Chang, 2010) and geological reference materials (e.g. Eggins et al., 1997). Synthetic solutions present the advantage of having certified concentrations, which should make the calculated results more accurate. In contrast, no geological reference material has certified values for its trace element contents. As a consequence, using as a reference for the signal calibration the element concentrations of geological reference materials make the analytical results dependent on the accuracy of the published concentrations. Nevertheless, Eggins et al. (1997) pointed out that using a natural reference material to calibrate the signal presents the advantage of sample/standard matrix matching. In this case, both calibration standard and samples are prepared the same way and they have similar major element compositions. In addition, all REE are present in natural proportions (i.e., higher abundances of the even elements relative to the odd elements), a situation that is not matched by the synthetic solutions.

In the initial stage of this study, we performed measurements of the geological reference material UB-N using these two calibration techniques. Figure 3 shows the deviation between our measured values and the values reported by Garbe-Schönberg (1993). Three dissolutions of UB-N were calibrated in two different ways: in the first case, we used commercial pure REE solutions (certified reference material CMS-1 with REE contents certified at $10 \mu \mathrm{g} \cdot \mathrm{g}^{-1}$, Inorganic Ventures) and in the second case, we used BHVO-2 as reference material. Figure 3 shows clearly that the BHVO-2 based calibration gives results similar within $\pm 5 \%$ to the values published by Garbe-Schönberg (1993), while those calculated using the REE solutions with different dilutions are always lower and strongly deviate from the published values, particularly so for the MREE. It is unclear what causes the large deviation observed when pure REE solutions are used to calibrate the signal. The lack of sample/standard matrix matching as highlighted by Eggins et al. (1997) may explain part of the discrepancy since the chemical separation performed here reduces the matrix effect but does not completely eliminate all non-REE (Figure 1). However, other more complex and not well understood effects obviously also contribute to the observed deviations, in particular those of the MREE.

Based on the experience shown in Figure 3, we calibrate the ICP-MS signal using the geological reference material BHVO-2. However, while calculated data for international rock material with very different REE contents were similar to published values for both LREE 
and HREE, data for the MREE were occasionally lower than the literature values $(\sim 10 \%$; Supplementary Table 3, Figure 4). We believe that this MREE depletion is due to an interference of organic material on the masses used for the measurement of the MREE. Indeed, during the REE elution, minute quantities of resin might fall into the beaker in which the REE fraction is collected. If the proportion of organic material present in the beaker varies between samples and between BHVO-2 and the samples run as unknown, the calculation made for the interfered masses is wrong and systematically biased. Addition of concentrated nitric acid and $\mathrm{H}_{2} \mathrm{O}_{2}$ to the sample after evaporation solved the problem, probably through destruction of organic molecules as visible with the noticed effervescence when $\mathrm{H}_{2} \mathrm{O}_{2}$ was added.

The final improvement to the measuring technique consisted in the systematic addition of Tm spike to all samples in order to better correct the signal drift during ICP-MS measurement. In Table 2, we report REE concentrations obtained with and without Tm spike addition for eight international geological reference materials (BE-N, BHVO-2, BIR-1, BR, BR-24, DTS-2, RGM-1 and UB-N). Results are also plotted as chondrite-normalized patterns in supplementary figure 1 . The second column in Table 2 reports REE contents measured without performing a drift correction based on an internal standard while data reported in the forth column were obtained after addition of a Tm spike prior to chemical separation. In the latter case, the Tm spike was used to correct for drift through time during ICP-MS measurements. For each set of data, we calculated the external reproducibility expressed as the relative standard deviation in \% (RSD) of the multiple independent determinations of each reference material (see Table 2).

As shown in supplementary figure 1, the REE data for all reference materials exhibit smooth patterns, generally consistent with the available literature values. However, the logarithmic scale used in this type of figure hides small differences and in Figures 5, 6 and 7, we choose to plot the deviations between our measurements and literature values to better evaluate the quality of the REE data obtained in this study. With the exception of the highly REE-depleted DTS-2, relative deviations for all REE in all samples are $<5 \%$ (Figures 5, 6, 7), and the RSD values for most REE are usually smaller than 5\%, even without using the Tm spike addition technique. Nevertheless, comparison of data obtained with and without spike addition shows that measurements performed using Tm spike are more reproducible, with lower RSD at about 1\% (Table 2). 
Results obtained for the most REE-depleted samples (BIR-1, UB-N and DTS-2, Figure 7) are also remarkably similar to high-quality data previously published. More specifically, our measurements of the reference materials BIR-1 and UB-N using the Tm spike are within 5\% of the previously published data (Garbe-Schönberg, 1993; Willbold and Jochum, 2005; Bayon et al., 2009). Eu and Tb values for the spiked UB-N are slightly lower than those published by Bayon et al. (2009), but are nevertheless consistent with the data published by Garbe-Schönberg (1993). For DTS-2, the most REE-depleted sample of all reference materials, few data have been published. Only Raczek et al. (2001) and Nakamura and Chang (2007) reported high-precision measurements for this sample, using ID-TIMS and ICP-MS respectively. When compared to these data, our results display differences generally smaller than 10\% (see Figure 7 and supplementary figure 1). Considering the low REE content of this sample and the scarcity of published data, it seems that a $\sim 10 \%$ difference is acceptable. Finally, the RSD values for DTS-2 are $<10 \%$ for the MREE and always $<5 \%$ for the other REE.

In summary, we believe that the most accurate and reproducible results are obtained (1) when the calibration is done with a geological reference material that follows the same chemical separation as the analyzed samples; (2) when concentrated nitric acid and $\mathrm{H}_{2} \mathrm{O}_{2}$ are added to the sample after chemical separation to destroy organic molecules coming from the resin; (3) when samples are spiked before chemical separation because it improves significantly the reproducibility of the analyses.

\section{Application to highly REE-depleted samples: Example of the New Caledonia peridotites}

Here we apply the method to the determination of REE contents in New Caledonia harzburgites. These rocks are characterized by extremely low REE concentrations, probably due to multiple melting events (Ulrich et al. 2010). Two samples previously analyzed by Ulrich et al. (2010) were selected and analyzed using the procedure presented in this study. Both are characterized by a U-shaped REE pattern similar to the reference material DTS-2. The REE concentrations are also similar to DTS-2, at the sub- $\mu \mathrm{g} \cdot \mathrm{g}^{-1}$ to ng. $\mathrm{g}^{-1}$ levels. Figure 8 show a comparison between results obtained using the classical method (i.e., analysis of all trace elements after rock dissolution but without chemical separation, as described by Chauvel et al., in press) and those obtained with the method developed in this study (data are available in the supplementary Table 4). Results obtained without chemical separation exhibit 
irregular chondrite-normalized patterns attributed to the very weak signal during data acquisition and to the enhanced effect of interferences on minute peaks. In contrast, the REE data measured after chemical separation define smooth patterns, with little to no difference between spiked and not spiked samples (Figure 8). This illustrates the improvements brought by isolation of the REE for highly REE-depleted rocks. These results demonstrate that an improved protocol can provide more reliable data for highly depleted samples and contribute to a better interpretation of the REE patterns in terms of geological processes.

\section{Conclusions}

We provide here a method for the accurate and reproducible measurement of REE in geological samples, including extremely REE-depleted rocks. This includes powder sample dissolution, REE-separation using ion-exchange columns loaded with cation resin, and measurement with a quadrupole ICP-MS. This protocol, applied to eight magmatic reference materials (BE-N, BHVO-2, BIR-1, BR, BR-24, DTS-2, RGM-1 and UB-N) gives good external errors $(<5 \%)$, even for the most depleted samples $(<10 \%)$. The results are in good agreement with high quality data published in literature. We finally demonstrate that for highly REE-depleted samples (sub ng. $\mathrm{g}^{-1}$ ), this procedure provides smooth chondritenormalized patterns in contrast to the irregular patterns obtained using a classical analysis performed on whole rocks.

\section{Acknowledgments}

The analytical work was supported by the Province Sud de la Nouvelle-Calédonie through funds to Christian Picard during his stay in New Caledonia. We thank Francis Coeur and Christèle Poggi for their help during the preparation of rock powders and during the analytical work in the chemistry lab at the Laboratoire de Géodynamique des Chaînes Alpines (LGCA). Very constructive comments made by both reviewers Bill McDonough and an anonymous one helped improving the final version of the manuscript. 


\section{$\underline{\text { References }}$}

Anders E. and Grevesse N. (1989)

Abundances of the elements - Meteoritic and solar. Geochimica et Cosmochimica Acta, 53, 197-214.

Aries S., Valladon M., Polvé M. and Dupré B. (2000)

A routine method for oxide and hydroxide interference corrections in ICP-MS chemical analysis of environmental and geological samples. Geostandards Newsletter, 24, 19-31.

Baker J., Waight T. and Ulfbeck D. (2002)

Rapid and highly reproducible analysis of rare earth elements by multiple collector inductively coupled plasma mass spectrometry. Geochimica et Cosmochimica Acta, 66, $3635-3646$.

Bayon G., Barrat J-A., Etoubleau J., Benoit M., Bollinger C. and Révillon S. (2009) Determination of Rare Earth Elements, Sc, Y, Zr, Ba, Hf and Th in geological samples by ICP-MS after Tm addition and alkaline fusion. Geostandards and Geoanalytical Research, $33,51-62$.

Barrat J-A., Keller F., Amossé J., Taylor R., Nesbitt R. and Hirata T. (1996)

Determination of rare earth elements in sixteen silicate reference samples by ICP-MS after Tm addition and ion exchange separation. Geostandards and Geoanalytical Research, 20, 133-139.

Carpentier M., Chauvel C., Maury R.C. and Mattielli N. (2009)

The "zircon effect" as recorded by the chemical and Hf isotopic compositions of Lesser Antilles forearc sediments. Earth and Planetary Science Letters, 287, 86-99.

Chauvel C., Bureau S. and Poggi C. (in press)

Comprehensive chemical and isotopic analyses of basalt and sediment reference materials. Geostandards and Geoanalytical Research, doi: 10.1111/j.1751-908X.2010.00086.x 
Cheatham M.M., Sangrey W.F. and White W.M. (1993)

Sources of error in external calibration ICP-MS analysis of geological samples and an improved non-linear drift correction procedure. Spectrochimica Acta Part B: Atomic Spectroscopy, 48, 487-506.

\section{Dulski P. (1994)}

Interferences of oxide, hydroxide and chloride analyte species in the determination of rare earth elements in geological samples by inductively coupled plasma-mass spectrometry. Fresenius' Journal of Analytical Chemistry, 350, 194-203.

Eggins S., Woodhead J., Kinsley L., Mortimer G., Sylvester P., McCulloch M., Hergt J. and Handler M. (1997)

A simple method for the precise determination of $\geq 40$ trace elements in geological samples by ICPMS using enriched isotope internal standardisation. Chemical Geology, 134, 311-326.

\section{Garbe-Schönberg C. (1993)}

Simultaneous determination of thirty-seven trace elements in twenty-eight international rock standards by ICP-MS. Geostandards and Geoanalytical Research, 17, 81-97.

\section{Henderson P. (1984)}

Rare earth element geochemistry. Elsevier (Amsterdam), 510 pp.

\section{Hirata T., Shimizu H., Akagi T., Sawatari H. and Masuda A. (1988)}

Precise determination of rare earth elements in geological standard rocks by inductively coupled plasma source mass spectrometry. Analytical Sciences, 4, 637-643.

\section{Jain J., Field M., Neal C., Ely J. and Sherrell R. (2000)}

Determination of the REE in geological reference materials DTS-1 (dunite) and PCC-1 (Peridotite) by ultrasonic and microconcentric desolvating nebulisation ICP-MS. Geostandards Newsletter, 24, 65-72. 
Jochum KP. and Nehring F. (2006)

BHVO-2: GeoReM preferred values (11/2006). GeoReM (http://georem.mpchmainz.gwdg.de).

Jochum KP. and Nohl U. (2008)

Reference materials in geochemistry and environmental research and the GeoReM database. Chemical Geology, 253, 50-53.

Nakamura K. and Chang Q. (2007)

Precise determination of ultra-low (sub-ng g-1) level rare earth elements in ultramafic rocks by quadrupole ICP-MS. Geostandards and Geoanalytical Research, 31, 185-197.

Newman K., Freedman P.A., Williams J., Belshaw N.S. and Halliday A.N. (2009)

High sensitivity skimmers and non-linear mass dependent fractionation in ICP-MS. Journal of Analytical Atomic Spectrometry, 24, 742-751.

Raczek I., Stoll B., Hofmann A. and Jochum KP. (2001)

High-precision trace element data for the USGS reference materials BCR-1, BCR-2, BHVO-1, BHVO-2, AGV-1, AGV-2, DTS-1, DTS-2, GSP-1 and GSP-2 by ID-TIMS and MIC-SSMS. Geostandards Newsletter, 25, 77-86.

Roy P., Balaram V., Kumar A.P., Satyanarayanan M. and Gnaneshwar Rao T. (2007) New REE and Trace Element Data on Two Kimberlitic Reference Materials by ICP-MS. Geostandards and Geoanalytical Research, 31, 261-273.

Ryder C., Gill J., Tepley III F., Ramos F. and Reagan M. (2006)

Closed-to open-system differentiation at Arenal volcano (1968-2003). Journal of Volcanology and Geothermal Research, 157, 75-93.

Strelow F.W.E. (1966)

Separation of trivalent rare earths plus Sc (iii) from Al, Ga, In, Tl, Fe, Ti, U and other elements by cation-exchange chromatography. Analytica Chimica Acta, 34, 387-393. 
Ulrich M., Picard C., Guillot S., Chauvel C., Cluzel D. and Meffre S. (2010)

Multiple melting stages and refertilization as indicators for ridge to subduction formation: The New Caledonia ophiolite. Lithos, 115, 223-236.

White W.M. (2005)

Geochemistry. John Hopkins University Press (Cornell), 721 pp.

Willbold M. and Jochum KP. (2005)

Multi-element isotope dilution sector field ICP-MS: A precise technique for the analysis of geological materials and its application to geological reference materials. Geostandards and Geoanalytical Research, 29, 63-82. 
Table and Supplementary Table captions

Table 1: Instrumental operating conditions.

Table 2: Analytical results for geochemical reference materials BE-N, BHVO-2, BIR-1, BR, BR-24, DTS-2, RGM-1 and UB-N. Methods used in the various publications: Baker et al. (2002): ICP-MS; Bayon et al. (2009): ICP-MS; Carpentier et al. (2009): ICP-MS; Chauvel et al. (in press): ICP-MS; Eggins et al. (1997): ICP-MS; Garbe-Schönberg (1993): ICP-MS; Nakamura and Chang (2007): ICP-MS; Raczek et al. (2001): ID/TIMS and MIC-SSMS; Roy et al. (2007): ICP-MS; Ryder et al. (2006): HR-ICP-MS; Willbold and Jochum (2005): ID/SFICP-MS. RSD = Relative Standard Deviation.

Supplementary Table 1: Dilution factor and amount of spike used for the various reference materials.

Supplementary Table 2: Table providing the selected isotope for the analysis of each element, the total blanks, the detection limits and the corrected interferences. Values in parentheses correspond to the highest contribution of the oxide interference on the total counts measured on masses $151(\mathrm{Eu}), 157(\mathrm{Gd}), 159(\mathrm{~Tb})$ and 163 (Dy).

Supplementary Table 3: Results obtained for BIR 1, BR-24, RGM-1 and BHVO-2 without any $\mathrm{H}_{2} \mathrm{O}_{2}$ added before analysis on the ICP-MS.

Supplementary Table 4: Comparison between results obtained on two highly REE-depleted harzburgites from New Caledonia analyzed using our procedure (with and without spike addition) and using the classical trace-element protocol as described by Chauvel et al. (in press).

\section{Figure Captions}


Figure 1: Elution curves for the REE as well as few other trace elements as measured on a UB-N sample using an ion-exchange column loaded with $2 \mathrm{~mL}$ of $200-400$ mesh Biorad ${ }^{\circledR}$ AG50W-X8 cation resin. The trace element contents were measured in $2 \mathrm{~mL}$ fractions all along the elution profile.

Figure 2: Detection limits plotted as sample equivalents and compared to the DTS-2 concentrations published by Nakamura and Chang (2007).

Figure 3: Deviation between the UB-N values published by Garbe-Schönberg (1993) and results obtained on three dissolutions of UB-N. The three measurements were calibrated using two different methods: (1) a calibration based on several dilutions of a commercial pure REE solution (certified reference material CMS-1 with REE contents at $10 \mu \mathrm{g} . \mathrm{g}^{-1}$, Inorganic Ventures) and (2) a BHVO-2 calibration.

Figure 4: MREE depletion as observed during the analysis of BIR-1, BR-24, RGM-1 and BHVO-2 when no $\mathrm{H}_{2} \mathrm{O}_{2}$ is added to destroy organic matter. Data are given in supplementary table 3 .

Figure 5: Comparison of our measured values for BE-N, BR and BR-24 with values from the literature as listed in Table 2, for both spiked and not spiked samples. The grey area corresponds to a relative deviation of 5\%. The error bars correspond to one standard deviation on duplicate analyses but in some cases, the error bar is smaller than the symbol.

Figure 6: Comparison of our measured values for BHVO-2 and RGM-1 with values from the literature as listed in Table 2, for both spiked and not spiked samples. The grey area corresponds to a relative deviation of 5\%. The error bars correspond to one standard deviation on duplicate analyses but in some cases, the error bar is smaller than the symbol.

Figure 7: Comparison of our measured values for BIR-1, UB-N and DTS-2 with values from the literature as listed in Table 2. The grey area corresponds to a relative deviation of $5 \%$ but for DTS-2 the field is extended to $10 \%$. The error bars correspond to one standard deviation on duplicate analyses but in some cases, the error bar is smaller than the symbol. 
Figure 8: Comparison of the chondrite-normalized patterns measured on two highly REEdepleted harzbugites from New Caledonia analyzed using our protocol (with and without spike addition) and using the classical trace-element protocol described by Chauvel et al. (in press). The chondritic values used for the normalization are from Anders and Grevesse (1989).

Supplementary figure 1: Chondrite-normalized patterns for BE-N, BHVO-2, BIR-1, BR, BR-24, DTS-2, RGM-1 and UB-N as measured in this study. Data acquired by others and listed in Table 2 are plotted for comparison. The chondritic values are from Anders and Grevesse (1989). 


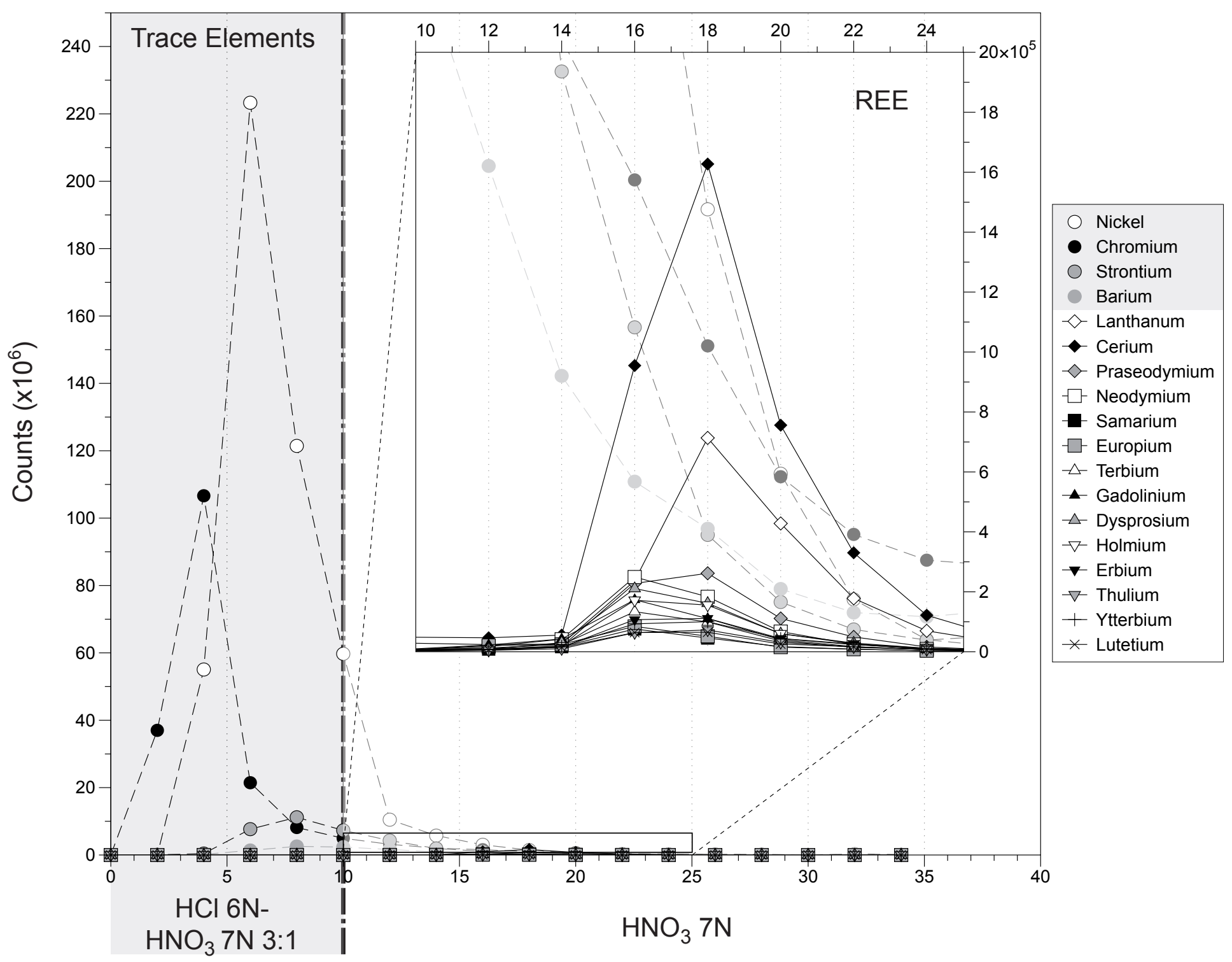

Eluant volume $(\mathrm{mL})$

Figure 1 
Figure 2

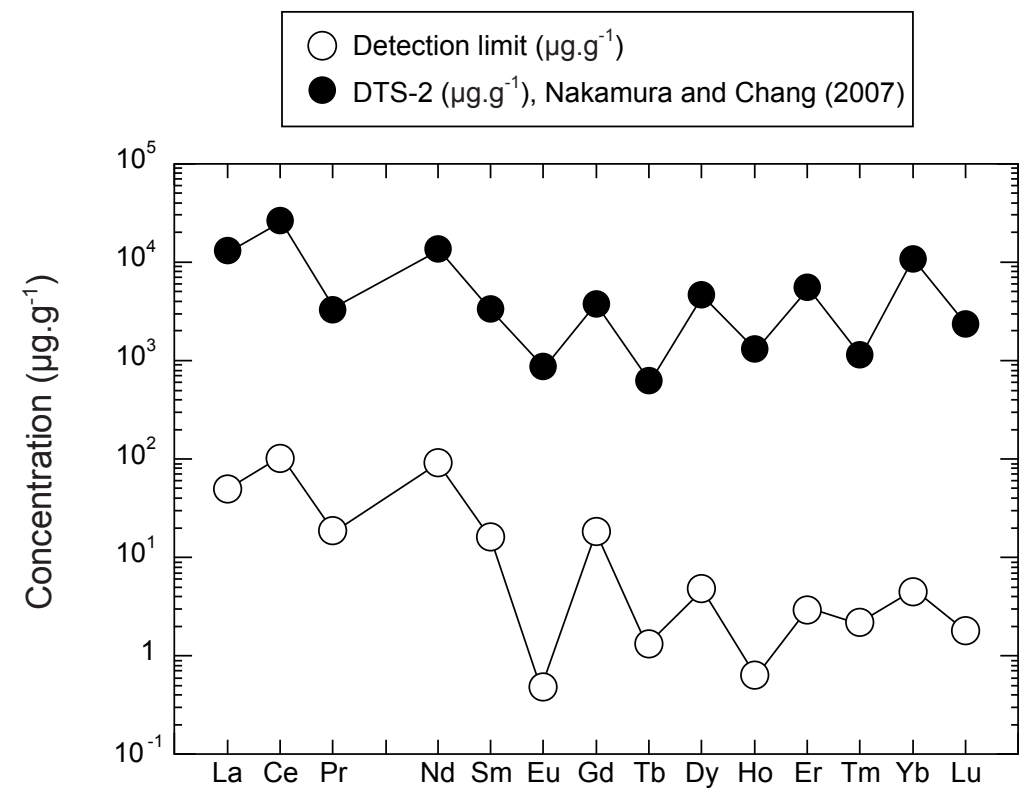


Figure 3

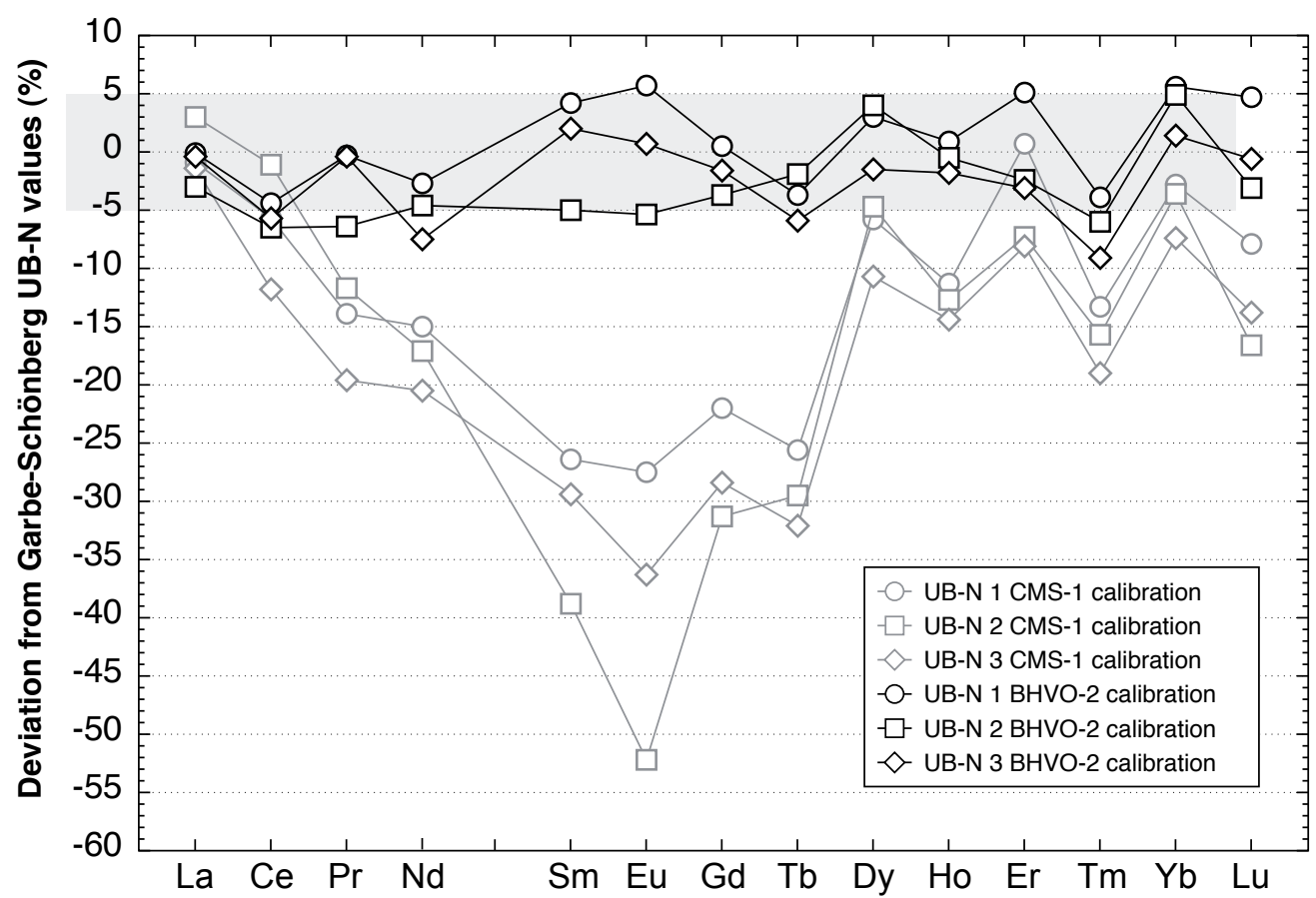


Figure 4

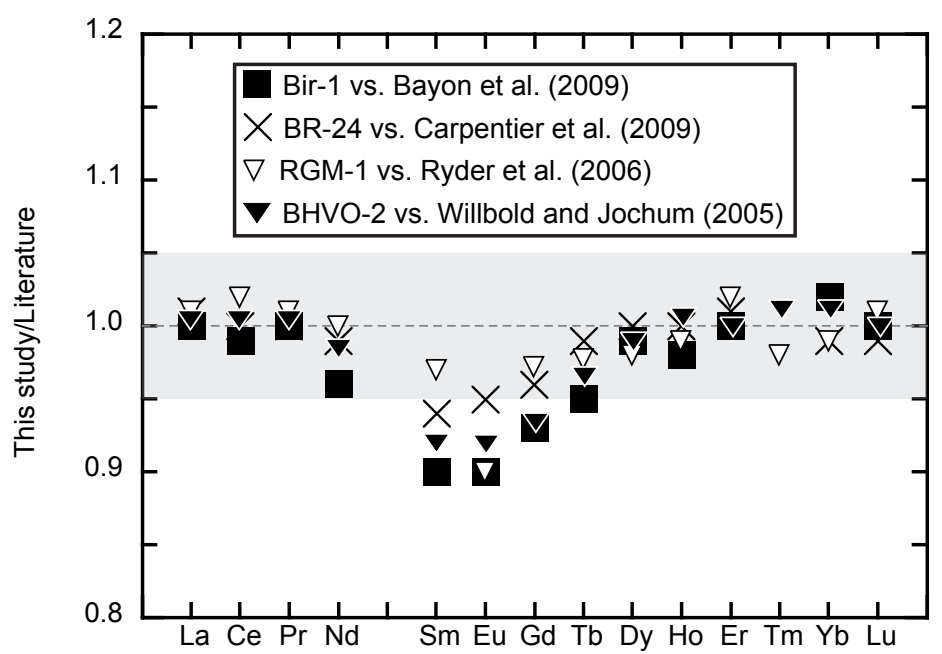



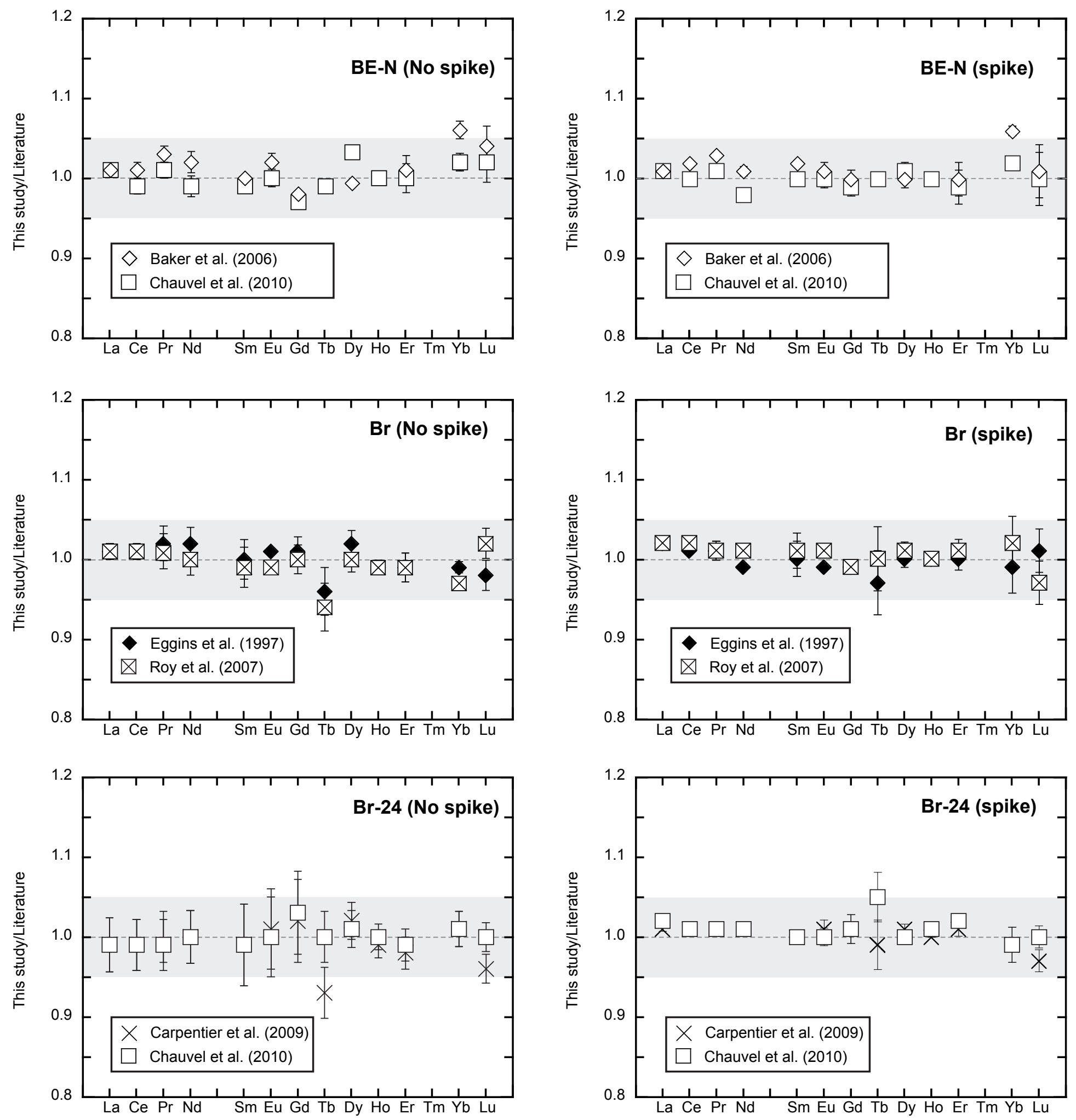

Figure 5 

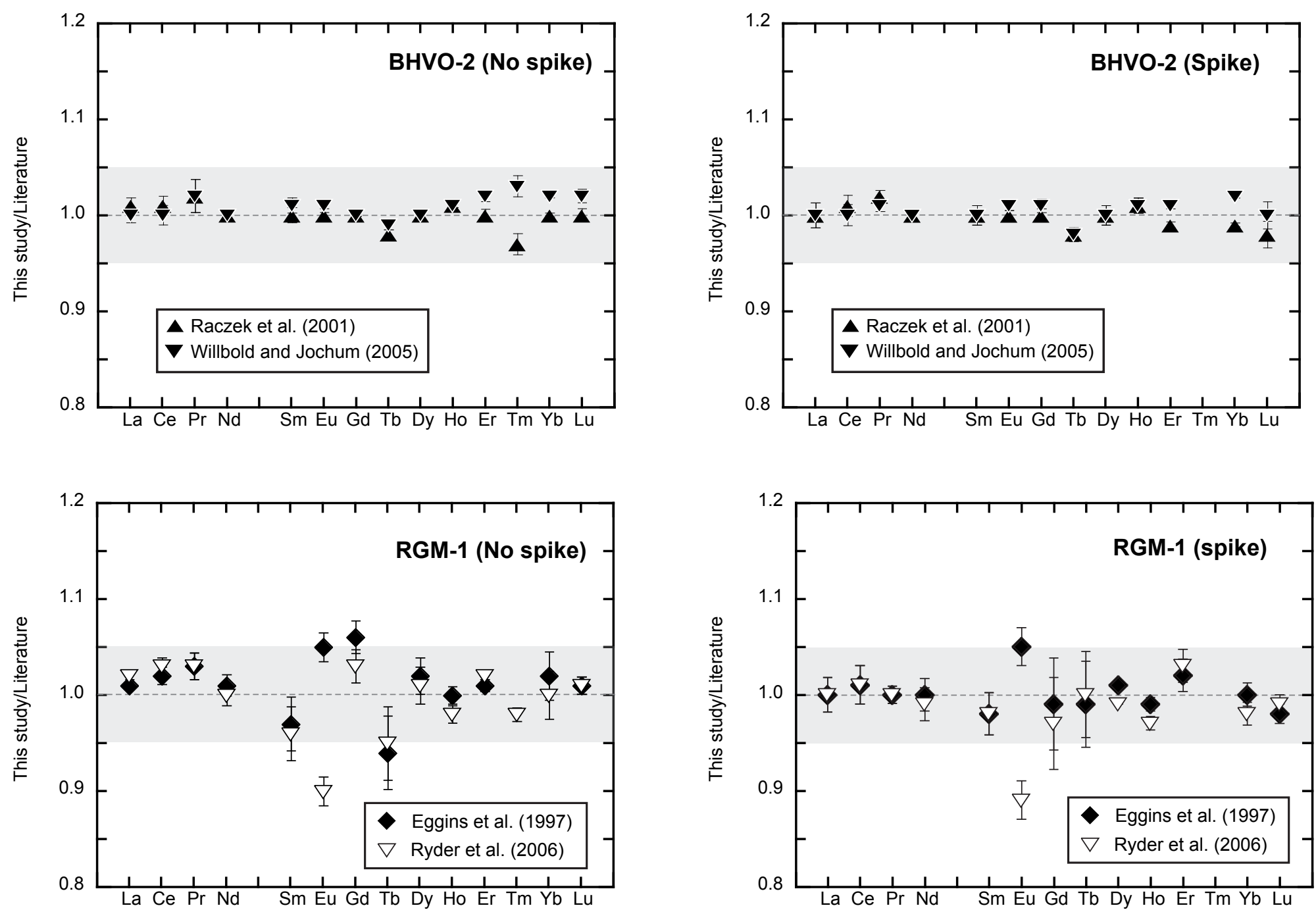

Figure 6 

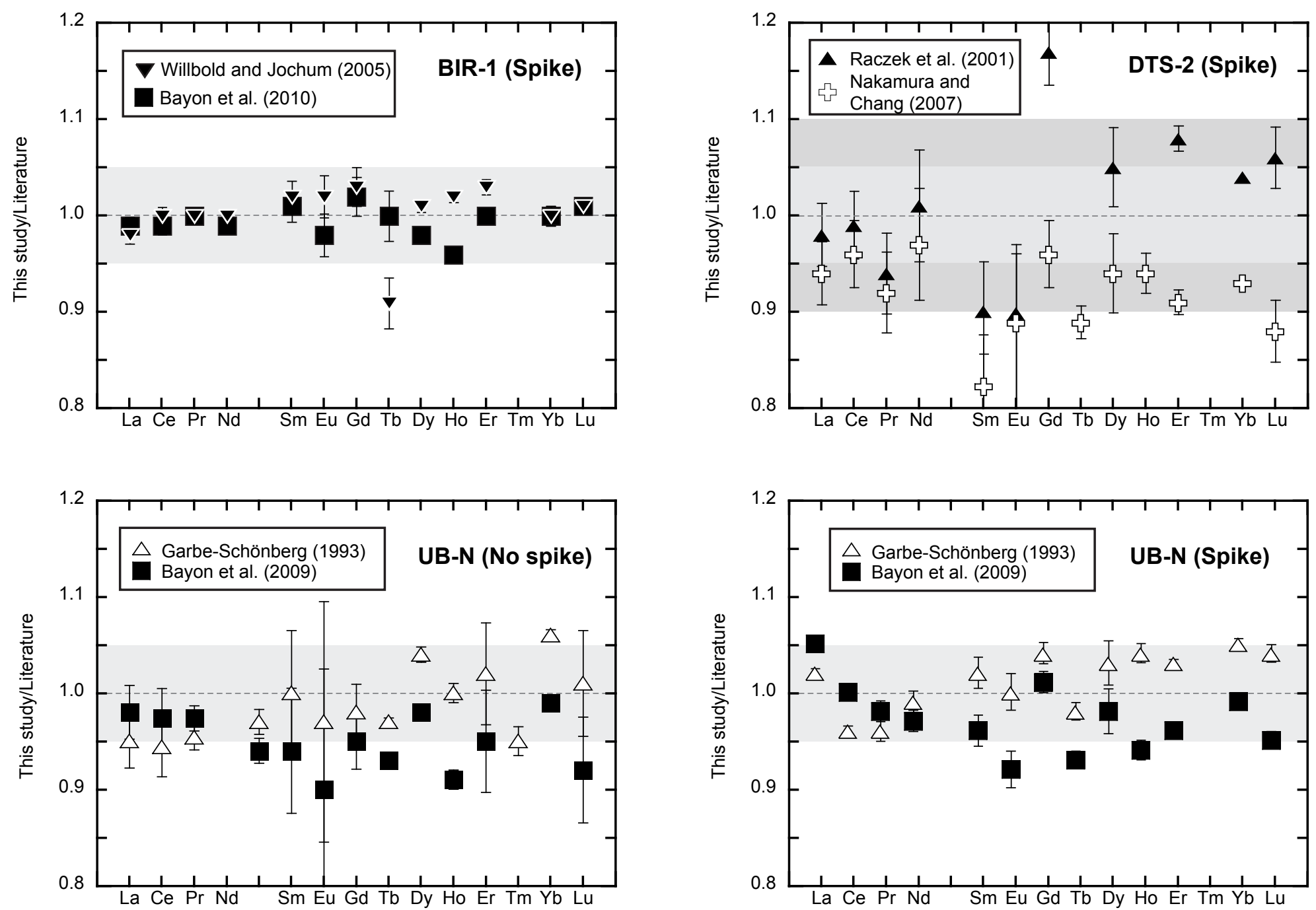

Figure 7 
Figure 8
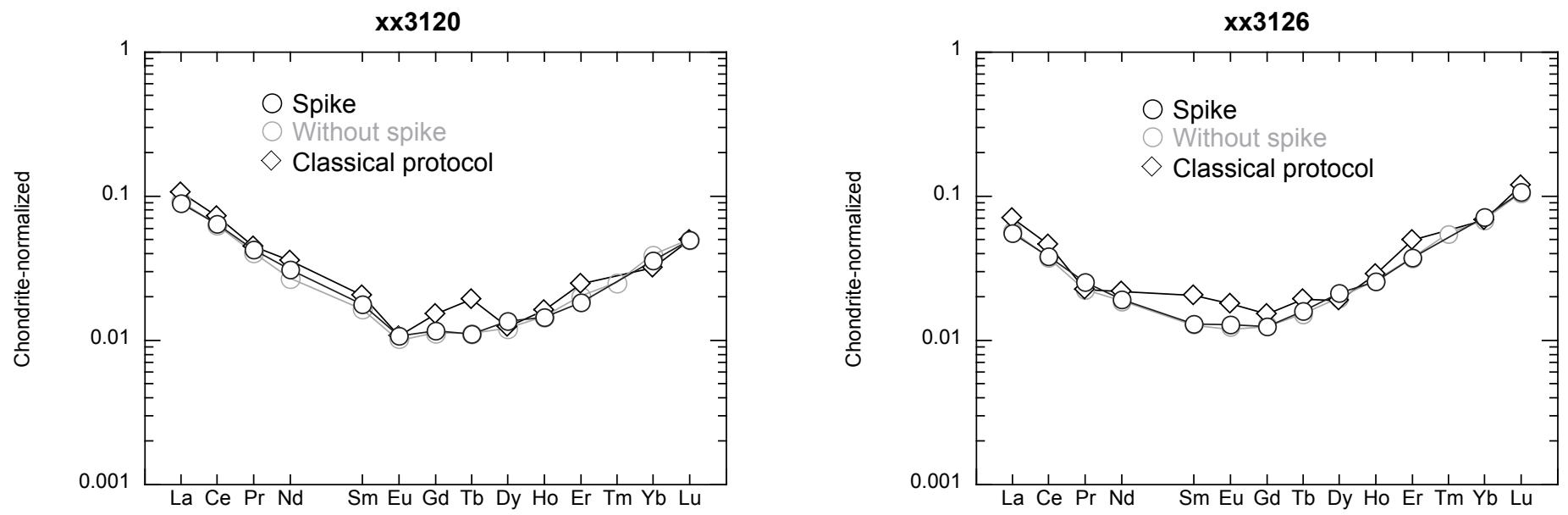

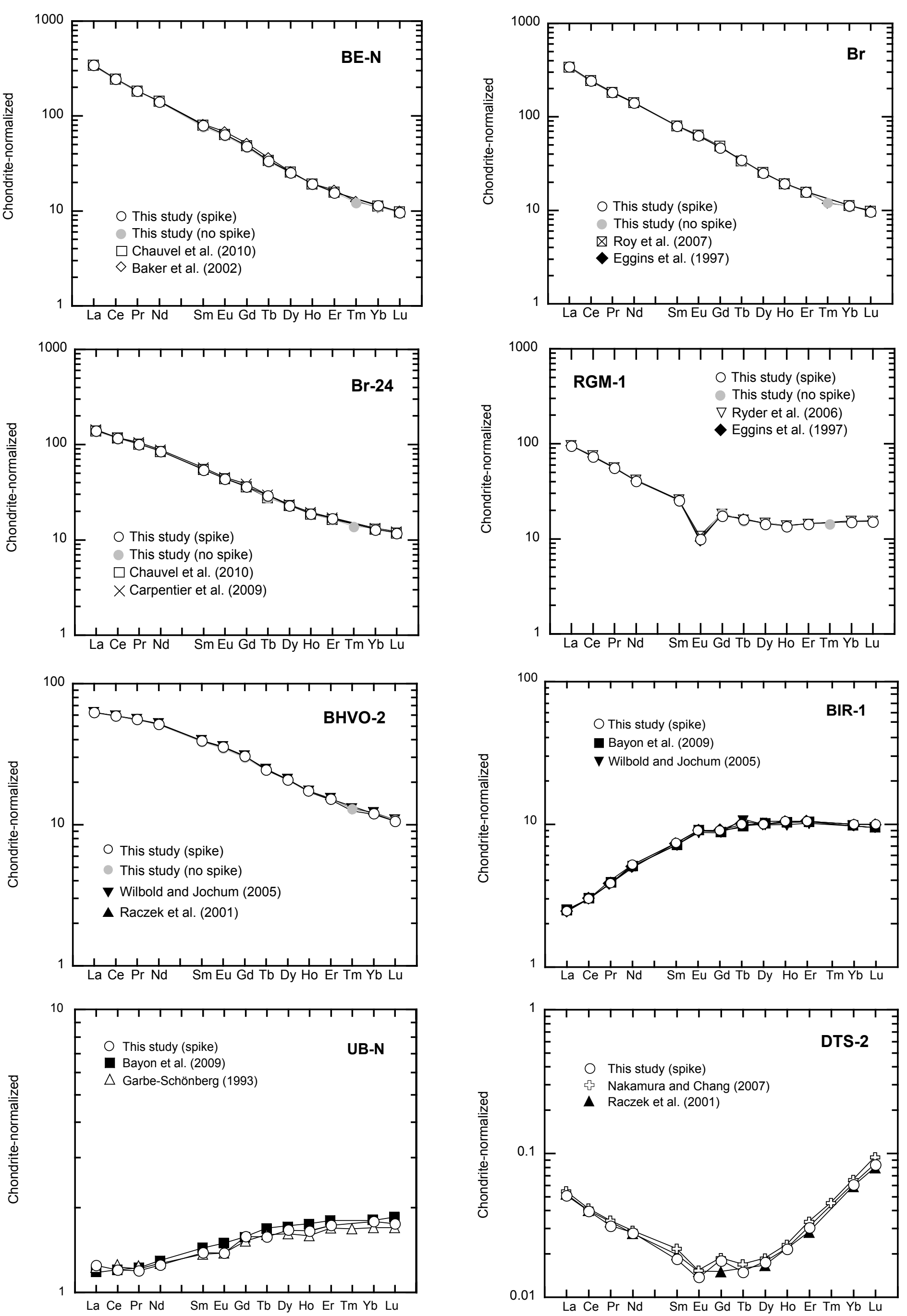

Supplementary figure 1: Chondrite-normalized patterns for BE-N, BHVO-2, BIR-1, BR, BR-24, DTS-2, RGM-1 and UB-N measured in this study. Data acquired by others and listed in Table 2 are plotted for comparison. C1-Chondrite values are from Anders and Grevesse (1989). 


\begin{tabular}{|c|c|}
\hline Parameter & Value \\
\hline Instrument & Agilent 7500ce \\
\hline Plasma power & $1550 \mathrm{~W}$ \\
\hline Reflected power & $1-5 \mathrm{~W}$ \\
\hline Torch & Quartz glass torch $2.5 \mathrm{~mm}$ with injector \\
\hline Sampling depth & $8-9 \mathrm{~mm}$ \\
\hline Plasma cool gas flow & 15 I. $\min ^{-1}$ \\
\hline Auxiliary gas flow & 0.90 I. $\mathrm{min}^{-1}$ \\
\hline Sample gas flow & 1.00 I. $\mathrm{min}^{-1}$ \\
\hline Carrier gas flow & 0.85 I. $\mathrm{min}^{-1}$ \\
\hline Makeup gas flow & 0.15 I. $_{\mathrm{min}^{-1}}$ \\
\hline Nebuliser & Quartz Micromist type $1 \mu$ L. $\min ^{-1}-400 \mu$ L. $\min ^{-1}$ \\
\hline Spray chamber & Quartz spray chamber, cooled at $2{ }^{\circ} \mathrm{C}$ \\
\hline Sample uptake rate & $0.12 \mathrm{ml} . \mathrm{min}^{-1}$ \\
\hline Sampling orifice & $1.0 \mathrm{~mm}$ (made of $\mathrm{Ni})$ \\
\hline Skimming orifice & $0.4 \mathrm{~mm}$ (made of $\mathrm{Ni})$ \\
\hline Typical sensitivity & 2 Mcps for ${ }^{7} \mathrm{Li}, 5 \mathrm{Mcps}$ for ${ }^{89} \mathrm{Y}$ and $2.5 \mathrm{Mcps}$ for ${ }^{205} \mathrm{TI}$ \\
\hline Oxide ratio $(156: 140)$ & $<1 \%$ \\
\hline Double charge $(70: 140)$ & $<3 \%$ \\
\hline Acquisition mode & Spectrum (multi Tune) \\
\hline Samples per peak & 3 \\
\hline Integration time per mass & $0.6 \mathrm{~s}$ from ${ }^{137} \mathrm{Ba}$ to ${ }^{163} \mathrm{Dy} ; 1.20 \mathrm{~s}$ from ${ }^{165} \mathrm{Ho}$ to ${ }^{175} \mathrm{Lu}$ \\
\hline Number of scans & 100 \\
\hline Calibration & External \\
\hline Internal standard & ${ }^{169} \mathrm{Tm}$ \\
\hline
\end{tabular}


Table 2: Analytical results for geochemical reference materials BE-N, BHVO-2, BIR-1, BR, BR-24, DTS-2, RGM-1 and UB-N.

\begin{tabular}{|c|c|c|c|c|c|c|}
\hline \multicolumn{7}{|c|}{ BE-N } \\
\hline \multirow{3}{*}{ Element } & \multicolumn{4}{|c|}{ This study } & \multicolumn{2}{|c|}{ References } \\
\hline & \multicolumn{2}{|c|}{ without spike $(n=4)$} & \multicolumn{2}{|c|}{ with spike $(n=4)$} & \multirow{2}{*}{$\begin{array}{l}\text { Chauvel et al. (in } \\
\text { press) }\end{array}$} & \multirow{2}{*}{ Baker et al. (2002) } \\
\hline & Average $\left(\mu \mathrm{g} \cdot \mathrm{g}^{-1}\right)$ & RSD (\%) & Average $\left(\mu \mathrm{g} \cdot \mathrm{g}^{-1}\right)$ & RSD (\%) & & \\
\hline $\mathrm{La}$ & 83.9 & 1.3 & 83.5 & 0.5 & 82.5 & 82.29 \\
\hline $\mathrm{Ce}$ & 154.0 & 1.3 & 155 & 0.1 & 155 & 152.3 \\
\hline $\operatorname{Pr}$ & 17.4 & 1.3 & 17.6 & 0.1 & 17.4 & 17.09 \\
\hline $\mathrm{Nd}$ & 66.2 & 2.1 & 66.6 & 0.6 & 67.7 & 65.98 \\
\hline Sm & 11.7 & 3.9 & 12.2 & 0.3 & 12.2 & 12.03 \\
\hline $\mathrm{Eu}$ & 3.57 & 4.1 & 3.67 & 1.1 & 3.67 & 3.619 \\
\hline Gd & 9.52 & 0.5 & 9.75 & 1.1 & 9.87 & 9.771 \\
\hline $\mathrm{Tb}$ & 1.21 & 3.4 & 1.25 & 0.7 & 1.26 & - \\
\hline Dy & 6.37 & 3.2 & 6.39 & 1.1 & 6.32 & 6.397 \\
\hline Ho & 1.06 & 1.8 & 1.09 & 0.3 & 1.09 & - \\
\hline Er & 2.57 & 2.0 & 2.56 & 2.1 & 2.59 & 2.572 \\
\hline $\mathrm{Tm}$ & 0.312 & 4.1 & - & - & - & - \\
\hline $\mathrm{Yb}$ & 1.81 & 4.5 & 1.88 & 0.6 & 1.84 & 1.771 \\
\hline $\mathrm{Lu}$ & 0.24 & 5.5 & 0.244 & 3.3 & 0.245 & 0.2411 \\
\hline
\end{tabular}

\begin{tabular}{|c|c|c|c|c|c|c|}
\hline \multicolumn{7}{|c|}{ BR } \\
\hline \multirow{3}{*}{ Element } & \multicolumn{4}{|c|}{ This study } & \multicolumn{2}{|c|}{ References } \\
\hline & \multicolumn{2}{|c|}{ without spike $(n=4)$} & \multicolumn{2}{|c|}{ with spike $(n=5)$} & \multirow{2}{*}{$\begin{array}{l}\text { Eggins et al. } \\
\text { (1997) }\end{array}$} & \multirow[b]{2}{*}{ Roy et al. (2002) } \\
\hline & Average $\left(\mu \mathrm{g} \cdot \mathrm{g}^{-1}\right)$ & RSD (\%) & Average $\left(\mu \mathrm{g} \cdot \mathrm{g}^{-1}\right)$ & RSD (\%) & & \\
\hline $\mathrm{La}$ & 83.2 & 1.0 & 83.6 & 0.2 & 82.1 & 82.13 \\
\hline $\mathrm{Ce}$ & 153.0 & 1.0 & 154.0 & 0.4 & 152 & 154 \\
\hline $\mathrm{Pr}$ & 17.7 & 2.2 & 17.6 & 1.2 & 17.36 & 17.52 \\
\hline $\mathrm{Nd}$ & 67.3 & 2.0 & 66.9 & 0.3 & 66.1 & 67.37 \\
\hline Sm & 12.1 & 2.5 & 12.2 & 2.2 & 12.11 & 12.2 \\
\hline $\mathrm{Eu}$ & 3.63 & 0.1 & 3.63 & 0.4 & 3.58 & 3.65 \\
\hline $\mathrm{Gd}$ & 9.63 & 1.8 & 9.49 & 0.3 & 9.57 & 9.61 \\
\hline $\mathrm{Tb}$ & 1.24 & 3.0 & 1.29 & 4.0 & 1.29 & 1.32 \\
\hline Dy & 6.4 & 1.6 & 6.36 & 1.1 & 6.3 & 6.4 \\
\hline Ho & 1.08 & 0.9 & 1.08 & 0.9 & 1.087 & 1.09 \\
\hline Er & 2.57 & 1.8 & 2.61 & 1.4 & 2.59 & 2.6 \\
\hline $\mathrm{Tm}$ & 0.308 & 2.6 & - & - & 0.303 & - \\
\hline $\mathrm{Yb}$ & 1.8 & 0.7 & 1.84 & 3.3 & 1.81 & 1.85 \\
\hline $\mathrm{Lu}$ & 0.246 & 1.9 & 0.243 & 2.7 & 0.251 & 0.24 \\
\hline
\end{tabular}

\begin{tabular}{|c|c|c|c|c|c|c|}
\hline \multicolumn{7}{|c|}{ BR 24} \\
\hline \multirow{3}{*}{ Element } & \multicolumn{4}{|c|}{ This study } & \multicolumn{2}{|c|}{ References } \\
\hline & \multicolumn{2}{|c|}{ without spike $(n=5)$} & \multicolumn{2}{|c|}{ with spike $(n=3)$} & \multirow{2}{*}{$\begin{array}{l}\text { Carpentier et al. } \\
\qquad(2009)\end{array}$} & \multirow{2}{*}{$\begin{array}{c}\text { Chauvel et al } \\
\text { (2010) }\end{array}$} \\
\hline & Average $\left(\mu \mathrm{g} \cdot \mathrm{g}^{-1}\right)$ & RSD (\%) & Average $\left(\mu \mathrm{g} \cdot \mathrm{g}^{-1}\right)$ & RSD (\%) & & \\
\hline La & 33.4 & 3.4 & 34.2 & 0.3 & 33.7 & 33.6 \\
\hline $\mathrm{Ce}$ & 72.7 & 3.2 & 74.3 & 0.3 & 73.9 & 73.9 \\
\hline Sm & 8.29 & 5.1 & 8.33 & 0.7 & 8.34 & 8.36 \\
\hline $\mathrm{Eu}$ & 2.54 & 5.0 & 2.56 & 1.1 & 2.51 & 2.53 \\
\hline Gd & 7.48 & 5.2 & 7.37 & 1.8 & 7.33 & 7.28 \\
\hline $\mathrm{Tb}$ & 1.03 & 3.2 & 1.09 & 3.1 & 1.10 & 1.03 \\
\hline Dy & 5.80 & 2.3 & 5.77 & 0.6 & 5.69 & 5.77 \\
\hline $\mathrm{Lu}$ & 0.297 & 1.8 & 0.298 & 1.4 & 0.31 & 0.297 \\
\hline
\end{tabular}

Methods used in the various publications: Baker et al. (2002): ICP-MS; Bayon et al. (2009): ICP-MS; Carpentier et al. (2009): ICP-MS; Chauvel et al. (in press): ICP-MS; Eggins et al. (1997): ICP-MS; Garbe-Schönberg (1993): ICP-MS; Nakamura and Chang (2007): ICP-MS; Raczek et al. (2001): ID/TIMS and MIC-SSMS; Roy et al. (2007): ICP-MS; Ryder et al. (2006): HR-ICPMS; Willbold and Jochum (2005): ID/SF-ICP-MS. RSD = Relative Standard Deviation. 
Table 2 (continued)

\begin{tabular}{|c|c|c|c|c|c|c|}
\hline \multicolumn{7}{|c|}{ RGM-1 } \\
\hline \multirow{3}{*}{ Element } & \multicolumn{4}{|c|}{ This study } & \multicolumn{2}{|c|}{ References } \\
\hline & \multicolumn{2}{|c|}{ without spike $(n=4)$} & \multicolumn{2}{|c|}{ with spike $(n=3)$} & \multirow{2}{*}{$\begin{array}{l}\text { Eggins et al. } \\
\qquad(1997)\end{array}$} & \multirow{2}{*}{$\begin{array}{l}\text { Ryder et al. } \\
\text { (2006) }\end{array}$} \\
\hline & Average $\left(\mu \mathrm{g} \cdot \mathrm{g}^{-1}\right)$ & RSD (\%) & Average $\left(\mu \mathrm{g} \cdot \mathrm{g}^{-1}\right)$ & RSD (\%) & & \\
\hline $\mathrm{La}$ & 23.5 & 0.4 & 23.2 & 1.8 & 23.2 & 23.1 \\
\hline $\mathrm{Ce}$ & 47.1 & 0.9 & 46.3 & 2.0 & 45.9 & 45.3 \\
\hline $\operatorname{Pr}$ & 5.47 & 1.4 & 5.34 & 0.9 & 5.32 & 5.33 \\
\hline $\mathrm{Nd}$ & 19.3 & 1.1 & 19.1 & 1.7 & 19.1 & 19.3 \\
\hline Sm & 3.82 & 2.8 & 3.88 & 2.2 & 3.94 & 3.96 \\
\hline $\mathrm{Eu}$ & 0.579 & 1.5 & 0.575 & 2.0 & 0.547 & 0.637 \\
\hline Gd & 3.78 & 1.7 & 3.54 & 4.8 & 3.56 & 3.66 \\
\hline $\mathrm{Tb}$ & 0.572 & 3.8 & 0.597 & 4.5 & 0.605 & 0.599 \\
\hline Dy & 3.67 & 1.9 & 3.62 & 0.1 & 3.6 & 3.65 \\
\hline Ho & 0.769 & 0.9 & 0.764 & 0.7 & 0.769 & 0.766 \\
\hline Er & 2.35 & 0.6 & 2.37 & 1.7 & 2.33 & 2.29 \\
\hline $\mathrm{Tm}$ & 0.364 & 0.7 & - & - & - & 0.37 \\
\hline $\mathrm{Yb}$ & 2.51 & 2.5 & 2.47 & 1.2 & 2.47 & 2.51 \\
\hline Lu & 0.393 & 0.9 & 0.383 & 1.0 & 0.386 & 0.388 \\
\hline
\end{tabular}

\begin{tabular}{|c|c|c|c|c|c|c|}
\hline \multicolumn{7}{|c|}{ BHVO-2 } \\
\hline \multirow{3}{*}{ Element } & \multicolumn{4}{|c|}{ This study } & \multicolumn{2}{|c|}{ References } \\
\hline & \multicolumn{2}{|c|}{ without spike $(n=4)$} & \multicolumn{2}{|c|}{ with spike $(n=5)$} & \multirow{2}{*}{$\begin{array}{l}\text { Willbold and } \\
\text { Jochum (2005) }\end{array}$} & \multirow{2}{*}{$\begin{array}{l}\text { Raczek et al. } \\
\text { (2001) }\end{array}$} \\
\hline & Average $\left(\mu g \cdot g^{-1}\right)$ & RSD (\%) & Average $\left(\mu g \cdot g^{-1}\right)$ & $\mathrm{RSD}(\%)$ & & \\
\hline $\mathrm{La}$ & 15.3 & 0.9 & 15.3 & 1.3 & 15.3 & 15.2 \\
\hline $\mathrm{Ce}$ & 37.8 & 1.1 & 37.8 & 1.1 & 37.6 & 37.5 \\
\hline $\operatorname{Pr}$ & 5.41 & 1.7 & 5.38 & 0.6 & 5.31 & 5.29 \\
\hline $\mathrm{Nd}$ & 24.6 & 1.3 & 24.5 & 0.3 & 24.5 & 24.5 \\
\hline Sm & 6.10 & 3.6 & 6.04 & 1.0 & 6.04 & 6.07 \\
\hline $\mathrm{Eu}$ & 2.06 & 3.0 & 2.06 & 0.5 & 2.05 & 2.07 \\
\hline Gd & 6.24 & 2.4 & 6.27 & 0.7 & 6.23 & 6.24 \\
\hline $\mathrm{Tb}$ & 0.922 & 1.7 & 0.92 & 0.7 & 0.933 & 0.936 \\
\hline Dy & 5.29 & 1.0 & 5.29 & 1.0 & 5.29 & 5.31 \\
\hline Ho & 0.978 & 0.8 & 0.977 & 0.8 & 0.964 & 0.972 \\
\hline Er & 2.55 & 0.6 & 2.52 & 0.3 & 2.49 & 2.54 \\
\hline $\mathrm{Tm}$ & 0.332 & 1.2 & - & - & 0.321 & 0.341 \\
\hline $\mathrm{Yb}$ & 1.99 & 1.2 & 1.98 & 0.2 & 1.95 & 2.00 \\
\hline Lu & 0.275 & 1.1 & 0.269 & 1.4 & 0.269 & 0.274 \\
\hline
\end{tabular}

\begin{tabular}{|c|c|c|c|c|c|c|}
\hline \multicolumn{7}{|c|}{ BIR-1 } \\
\hline \multirow{3}{*}{ Element } & \multicolumn{4}{|c|}{ This study } & \multicolumn{2}{|c|}{ References } \\
\hline & \multicolumn{2}{|c|}{ without spike $(n=4)$} & \multicolumn{2}{|c|}{ with spike $(n=3)$} & \multirow{2}{*}{$\begin{array}{l}\text { Willbold and } \\
\text { Jochum (2005) }\end{array}$} & \multirow{2}{*}{$\begin{array}{c}\text { Bayon et al. } \\
\text { (2009) }\end{array}$} \\
\hline & Average $\left(\mu g \cdot g^{-1}\right)$ & RSD (\%) & Average $\left(\mu \mathrm{g} \cdot \mathrm{g}^{-1}\right)$ & RSD (\%) & & \\
\hline $\mathrm{La}$ & - & - & 0.595 & 0.9 & 0.604 & 0.600 \\
\hline $\mathrm{Ce}$ & - & - & 1.88 & 0.9 & 1.89 & 1.91 \\
\hline $\operatorname{Pr}$ & - & - & 0.374 & 0.3 & 0.374 & 0.372 \\
\hline $\mathrm{Nd}$ & - & - & 2.37 & 0.6 & 2.37 & 2.40 \\
\hline $\mathrm{Sm}$ & - & - & 1.11 & 1.6 & 1.09 & 1.102 \\
\hline $\mathrm{Eu}$ & - & - & 0.518 & 2.2 & 0.508 & 0.530 \\
\hline Gd & - & - & 1.84 & 2.0 & 1.79 & 1.81 \\
\hline $\mathrm{Tb}$ & - & - & 0.366 & 2.6 & 0.399 & 0.366 \\
\hline Dy & - & - & 2.55 & 0.6 & 2.52 & 2.59 \\
\hline $\mathrm{Ho}$ & - & - & 0.571 & 0.6 & 0.559 & 0.591 \\
\hline Er & - & - & 1.74 & 0.8 & 1.68 & 1.74 \\
\hline Tm & - & - & - & - & - & - \\
\hline $\mathrm{Yb}$ & - & - & 1.63 & 1.0 & 1.62 & 1.63 \\
\hline Lu & - & - & 0.245 & 0.7 & 0.241 & 0.243 \\
\hline
\end{tabular}


Table 2 (continued)

\begin{tabular}{|c|c|c|c|c|c|c|}
\hline \multicolumn{7}{|c|}{ UB-N } \\
\hline \multirow{3}{*}{ Element } & \multicolumn{4}{|c|}{ This study } & \multicolumn{2}{|c|}{ References } \\
\hline & \multicolumn{2}{|c|}{ without spike $(n=3)$} & \multicolumn{2}{|c|}{ with spike $(n=5)$} & \multirow{2}{*}{$\begin{array}{c}\text { Garbe-Schönberg } \\
\text { (1993) }\end{array}$} & \multirow{2}{*}{$\begin{array}{l}\text { Bayon et al. } \\
\text { (2009) }\end{array}$} \\
\hline & Average $\left(\mu g . g^{-1}\right)$ & RSD (\%) & Average $\left(\mu g \cdot g^{-1}\right)$ & RSD (\%) & & \\
\hline $\mathrm{La}$ & 0.286 & 2.8 & 0.306 & 0.4 & 0.3 & 0.29 \\
\hline $\mathrm{Ce}$ & 0.754 & 0.6 & 0.770 & 0.5 & 0.8 & 0.77 \\
\hline $\operatorname{Pr}$ & 0.115 & 1.2 & 0.115 & 1.1 & 0.12 & 0.118 \\
\hline $\mathrm{Nd}$ & 0.579 & 1.3 & 0.594 & 1.1 & 0.60 & 0.613 \\
\hline Sm & 0.210 & 6.5 & 0.214 & 1.6 & 0.21 & 0.222 \\
\hline $\mathrm{Eu}$ & 0.078 & 9.5 & 0.080 & 1.9 & 0.08 & 0.087 \\
\hline Gd & 0.305 & 2.9 & 0.323 & 1.1 & 0.31 & 0.32 \\
\hline $\mathrm{Tb}$ & 0.058 & 0.4 & 0.059 & 0.9 & 0.06 & 0.063 \\
\hline Dy & 0.425 & 0.8 & 0.424 & 2.3 & 0.41 & 0.434 \\
\hline Ho & 0.090 & 1.0 & 0.094 & 1.0 & 0.09 & 0.099 \\
\hline Er & 0.284 & 5.3 & 0.287 & 0.4 & 0.28 & 0.299 \\
\hline $\mathrm{Tm}$ & 0.041 & 1.5 & - & - & 0.043 & - \\
\hline $\mathrm{Yb}$ & 0.295 & 0.6 & 0.295 & 0.5 & 0.28 & 0.299 \\
\hline $\mathrm{Lu}$ & 0.043 & 5.5 & 0.045 & 0.9 & 0.043 & 0.047 \\
\hline
\end{tabular}

\begin{tabular}{|c|c|c|c|c|c|c|}
\hline \multicolumn{7}{|c|}{ DTS-2 } \\
\hline \multirow{3}{*}{ Element } & \multicolumn{4}{|c|}{ This study } & \multicolumn{2}{|c|}{ References } \\
\hline & \multicolumn{2}{|c|}{ without spike $(n=0)$} & \multicolumn{2}{|c|}{ with spike $(n=5)$} & \multirow{2}{*}{$\begin{array}{l}\text { Raczek et al. } \\
\quad(2001)\end{array}$} & \multirow{2}{*}{$\begin{array}{l}\text { Nakamura et } \\
\text { Chang (2007) }\end{array}$} \\
\hline & Average $\left(\mu \mathrm{g} \cdot \mathrm{g}^{-1}\right)$ & RSD (\%) & Average $\left(\mu \mathrm{g} \cdot \mathrm{g}^{-1}\right)$ & RSD (\%) & & \\
\hline $\mathrm{La}$ & - & - & 0.0124 & 3.3 & 0.0127 & 0.0132 \\
\hline $\mathrm{Ce}$ & - & - & 0.0252 & 3.5 & 0.0254 & 0.0263 \\
\hline $\operatorname{Pr}$ & - & - & 0.0030 & 4.2 & 0.0032 & 0.0033 \\
\hline $\mathrm{Nd}$ & - & - & 0.0132 & 5.8 & 0.0131 & 0.0136 \\
\hline $\mathrm{Sm}$ & - & - & 0.0027 & 8.2 & 0.00302 & 0.0033 \\
\hline Eu & - & - & 0.0008 & 9.0 & 0.00087 & 0.0009 \\
\hline Gd & - & - & 0.0037 & 3.5 & 0.00304 & 0.0038 \\
\hline Tb & - & - & 0.0006 & 1.7 & - & 0.0006 \\
\hline Dy & - & - & 0.0044 & 4.1 & 0.00419 & 0.0047 \\
\hline Ho & - & - & 0.0012 & 2.1 & - & 0.0013 \\
\hline Er & - & - & 0.0051 & 1.3 & 0.00465 & 0.0055 \\
\hline Tm & - & - & - & - & - & 0.0012 \\
\hline $\mathrm{Yb}$ & - & - & 0.01 & 0.1 & 0.00963 & 0.0107 \\
\hline Lu & - & - & 0.0021 & 3.2 & 0.002 & 0.0023 \\
\hline
\end{tabular}

